\title{
Effect of dietary phytoestrogens, feed restriction, and their interaction on reproductive status of broiler pullets
}

\author{
A. D. Madnurkar ${ }^{1}$, A. S. Shinde ${ }^{1}$, L. Chouhan ${ }^{2}$, V. Singh ${ }^{3}$, J. Mohan ${ }^{1}$ and R. P. Moudgal ${ }^{1}$
}

1. Division of Poultry Science, Central Avian Research Institute, Izatnagar - 243 122, Uttar Pradesh, India; 2. Department of Poultry Science, College of Veterinary Science and Animal Science, Mhow, Indore, Madhya Pradesh, India; 3. Division of Poultry Science, ICAR Research Complex for NEH Region, Tripura Centre, Lembucherra, Agartala, Tripura, India.

Corresponding author: A. S. Shinde, e-mail: anil.ivri@gmail.com, ADM:madnurkararjun@gmail.com, LC:drlaxmimhow@gmail.com, VS: vinvet1@gmail.com, JM: mohanjagjag@rediffmail.com, RPM:rpmudgal@hotmail.com Received: 14-08-2014, Revised: 02-11-2014, Accepted: 10-11-2014, Published online: 08-12-2014

doi: 10.14202/vetworld.2014.1041-1046. How to cite this article: Madnurkar AD, Shinde AS, Chouhan L, Singh V, Mohan J, Moudgal RP (2014) Effect of dietary phytoestrogens, feed restriction and their interaction on reproductive status of broiler pullets, Veterinary World 7(12): 1041-1046.

\begin{abstract}
Background and Aim: A major problem faced by the broiler industry around the world is a lowered reproductive fitness of breeding hens which can cause major economic impact in terms of lowered hatchable egg production. In broiler breeders, a lot of the selection pressure has been exerted on growth, conformation and feed efficiency as a result broiler breeder hens are prone to several metabolic disorders and reproductive anomalies. Present study was conducted to assess the effect of phytoestrogen, feed restrictions (75\% of their control ad libitum), and their interaction on reproductive parameters in high and low body weight broiler breeder hens.
\end{abstract}

Materials and Methods: One hundred twenty-eight healthy female broiler breeder pullets were divided randomly into eight groups from the same hatch and strain. They were transferred to individual laying cages. Birds received ad libitum drinking water and feeding, depend on divided group i.e., ad libitum or restricted feeding (75\% of control ad libitum) counterpart separately for heavy or low body weight till first egg laid in respective groups. Experimental diets made with practical feed ingredients as per institution recommendation (broiler breeder ration) as per experimental planning.

Results: Phytoestrogen significantly $(\mathrm{p}<0.05)$ improved egg number and size in broiler breeding hens by checking reproductive anomalies (internal laying, double hierarchy, and follicular atresia), restructuring ovarian, and oviductal functional development besides improved physiological maturation of infundibulum. Unlike phytoestrogen, feed restriction as expected delayed the age of sexual maturity but helped in a reduction of ovary weight, number of yellow follicle, number of atretic yellow follicle, incidence of double hierarchy, and internal ovulation. Interaction between phytoestrogen and feed restriction did not give any additional remunerative advantage.

Conclusions: It is concluded that phytoestrogens and limited feed restriction likely to improve reproductive efficiency around age of sexual maturity by overcoming the reproductive anomalies and modulating the ovarian and oviduct maturation favorably in broiler breeder hen.

Keywords: broiler breeder, feed restriction, phytoestrogen, reproductive parameters.

\section{I ntroduction}

In broiler breeders, a lot of the selection pressure has been exerted on growth, conformation and feed efficiency making them more prone to several metabolic disorders and reproductive anomalies. Selection for growth rate in the broiler chicken is associated with poor egg laying that is a consequence of obesity and a disorganized ovarian follicular hierarchy. The number of hierarchical yellow follicles increases with selection for large body size in avian species $[1,2]$. Ovary bearing large number of follicles is a serious problem for broiler breeder hens [3,4] as the additional follicles result in multiple ovulation and poor egg production because potential egg yolks are lost internally or through the production of soft-shelled, misshapen, and double-yolked eggs that cannot be harvested or

Copyright: The authors. This article is an open access article licensed under the terms of the Creative Commons Attributin License (http:// creative commons.org/licenses/by/2.0) which permits unrestricted use, distribution and reproduction in any medium, provided the work is properly cited. used for incubation [5]. In egg-type hens, there is little evidence of ovarian dysfunction, while in meattype hens various reproductive disorders have been described. The incidence of arrhythmic sequences was reported to be higher in meat-type hens than in eggtype hens [6]. The presence of two eggs in the oviduct at one time was reported by Jaap and Muir [6].

In birds, estrogen is proposed to be a pivotal factor causing most of the reproductive transformation associated with pubertal events. First, estrogen influences the production of yolk precursors (building blocks of yolk production) in the liver of the bird. The liver visibly enlarges and becomes paler as its fat content increases for the production of egg yolk lipids. Second, the oviduct increases in size, so it is ready to receive ovulated follicles. Though in the hens, the ovarian follicles committed to ovulate in an ordered hierarchical manner, in standard broiler breeder hens genetically selected for high growth rate, generally the reproductive function is altered. Feed restriction is needed during reproductive development to limit 
the formation of excessive numbers of ovarian yellow follicles arranged in multiple hierarchies [7]. Low egg production during early lay in broiler breeders fed ad libitum is associated with multiple ovulations caused by the presence of at least two hierarchies of ovarian yellow follicles. Restricting the quantity of food during early lay period limits, the maturation of yellow follicles and in turn reduces the incidence of double ovulations as well as internal laying, these impacts lead to overall increase in the number of eggs laid [3].

In short to tackle these foregoing problems in broiler breeder is the need of the day for the broiler industry. It is essential to understand the cause of these problems and to develop operational exogenous strategies to tackle these vexing problem encountered in particular around the age of sexual maturity. Reducing such losses could well translate into extra egg/chicks and improved profit margin for poultry farmers.

Keeping in view the foregoing background, the present study has been carried out to assess the effect of phytoestrogen, feed restrictions (75\% of their control ad libitum), and their interaction on reproductive parameters in high and low body weight broiler breeder hens.

\section{Materials and Methods}

\section{Ethical approval}

Experiments were carried out in accordance with the guidelines laid down by the Institute Animal Ethics committee for the use of animal subjects or that procedures were in compliance with at least the declaration of the National Institutes of Health Guide for Care.

\section{Phytoestrogen supplementation}

Drug: Isoflav-CR (60 mg soy isoflavones/capsule, Raptakos, Brett \& Co. Ltd. India). Dose level was provided at the rate of $30 \mathrm{ppm}$ in all the relevant groups. In our lab, we have already tried $10 \mathrm{ppm}$, 20 ppm phytoestrogen level which has a good result on reproductive status (Data not published yet), so we tried more than that level.

\section{Birds and experiment}

The experiment started from 19 weeks to 25 weeks of age (i.e., 7 weeks) of birds. One hundred twenty-eight healthy female broiler breeder pullets were divided randomly into eight groups from the same hatch and strain. They were transferred to individual laying cages and each group having 16 birds. Birds received ad-libitum drinking water, and feeding depends on divided group i.e. ad libitum or restricted feeding (feeding shown in Flow Diagram-1. as per divided group). Restricted feeding in relevant groups provided at the level of $75 \%$ of their control ad libitum counterpart separately for heavy or low body weight till first egg laid in respective groups. Experimental diets made with practical feed ingredients as per institution recommendation (broiler breeder ration) with free access to water and feed as per experimental planning. Feed formulation and composition for breeder layer ration given in Table-1. At the beginning of the experiment, all the birds were weighed in an automatic electronic weighing balance and were divided into low body weight ( $\mathrm{n}=64$ lowermost) and high body weight ( $\mathrm{n}=64$ uppermost). Treatment given as per groups depicted in Flow Diagram-1. At 25 week, six hens from each of the group sacrificed and were evaluated using the standard procedures for the reproductive parameters: Ovary weight (on dissecting out yellow follicles), oviduct weight, number

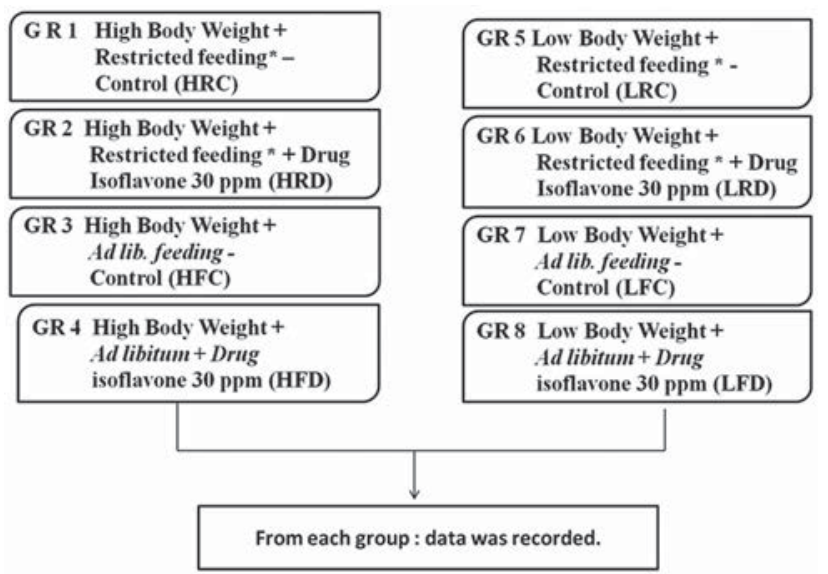

Flow Diagram-1: Feeding of different groups.

Table-1: Formula and chemical composition of broiler breeder ration.

\begin{tabular}{lc}
\hline Ingredients (kg) & For $\mathbf{1 0 0 ~} \mathbf{~ k g ~ f e e d ~}$ \\
\hline Maize & 56.5 \\
De- oiled rice bran & 6.73 \\
Soybean & 20 \\
Sunflower & 3 \\
Fish meal & 4 \\
Oyster shell & 0.63 \\
Marble chips & 4 \\
Limestone & 3.8 \\
Digestible crude protein & 0.7 \\
Salt & 0.25 \\
DL-methionine & 0.02 \\
*TM. premix 1 & 0.125 \\
**Vitamin premix 2 & 0.15 \\
B complex & 0.015 \\
Ch. chloride & 0.03 \\
Toxin binder & 0.05 \\
Total & 100 \\
Nutrient composition & \\
Crude protein (\%) & 17.33 \\
M energy Kcal/kg & 2607.64 \\
Calcium (\%) & 3.51 \\
Available phosphorus (\%) & 0.36 \\
Lysine (\%) & 0.93 \\
Methionine (\%) & 0.38 \\
\hline
\end{tabular}

* Trace mineral mixture provided $(\mathrm{mg} / \mathrm{kg}$ diet):

$\mathrm{Fe}-80 \mathrm{mg} ; \mathrm{I}-1.2 \mathrm{mg}$; $\mathrm{Mn}-65 \mathrm{mg}, \mathrm{Zn}$ and $\mathrm{Cu}-8$ mg. **Vitamin mixture provided ( $\mathrm{mg} / \mathrm{kg}$ diet): Chlorine chloride - 500; Niacin - 12, Pyridoxine hydrochloride - 1.6, vitamin A - $8250 \mathrm{IU}$, vitamin B1-0.08, vitamin B2-5, vitamin B12-8, vitamin D3-1200 IU, vitamin E - 10 and vitamin $\mathrm{K}-1$. Enzyme was added $(\mathrm{mg} / \mathrm{kg})$ diet-Multienzyme - 500; xylanase - 20; phytase - 100 
of yellow follicles, number of yellow atretic follicles, presence of internal ovulation, and presence of abnormal hierarchy.

HRC: High body weight + restricted feeding* control; HRD: High body weight + restricted feeding* + drug isoflavone 30 ppm; HFC: High body weight + ad libitum feeding - control; HFD: High body weight + ad libitum + drug isoflavone 30 ppm; LRC: Low body weight + restricted feeding* - control; LRD: Low body weight + restricted feeding* + drug isoflavone 30 ppm; LFC: Low body weight + ad libitum feeding - control; LFD: Low body weight + ad libitum + drug isoflavone 30 ppm.

\section{Statistical analysis}

The gross reproductive parameter among the treatments was analyzed using one-way statistical analysis [8] and means compared using Duncan's multiple range test [9].

\section{Results and Discussions}

Effect of phytoestrogens ( $30 \mathrm{ppm}$ ), feed restriction and their interaction on ovarian and follicular status (19-25 weeks)

Ovary status tus are available in Table-2. Phytoestrogen induced significant $(\mathrm{p}<0.05)$ drop in ovary weight of heavier birds (HFD) but this difference was numerical only in LFD as compared to HFC and LFC, respectively. Phytoestrogen administration might have suppressed the level of gonadotropins hormone through negative feedback mechanism and thus in turns there could be lesser ovary weight on account of under stimulation by the gonadotropins.

Feed restriction in HRC and LRC birds significantly $(\mathrm{p}<0.05)$ reduced ovary weight in comparison to HFC and LFC birds. Our results are confirmed by Sun et al. [10], who described pullets fed ad libitum had 31.55 and $13.53 \mathrm{~g}$ heavier ovary weight compared with the feed-restricted pullets at first egg. Feed restriction has limited the body weight of breeding birds at sexual maturity and prevents over-stimulation of the ovary.

Interaction of phytoestrogen and feed restriction in HRD birds reduced ovary weight significantly $(p<0.05)$ in comparison with control HFC but only numerical decrease was noticed in LRD as compared to LFC birds. Phytoestrogen and feed restriction together did not provide additional drop in ovarian weight in comparison to either phytoestrogen or feed restriction.

\section{Number of yellow follicles}

The results on the number of yellow follicles are given in Table-2. Phytoestrogen significantly $(\mathrm{p}<0.05)$ reduced number of yellow follicles in HFD and LFD birds in comparison to their controls HFC and LFC, lesser number of yellow follicles is present in the
The results on ovary and ovarian follicular starespectively. In high egg producing hens, generally

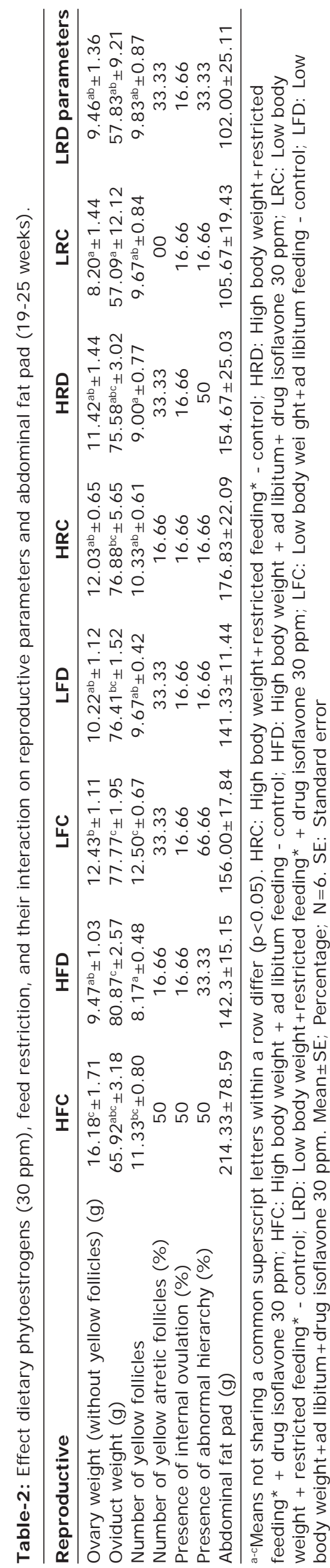

Veterinary World, EISSN: 2231-0916 
ovary as compared to poor laying hens. Thus, it is concluded that phytoestrogen favor the restructuring the developmental pattern of growing ovarian follicles in the best interest of getting better egg production, in fact, which we received under the present study.

Feed restriction has no any effect in HRC, but LRC indicated a significant $(\mathrm{p}<0.05)$ reduction in a number of yellow follicles as compared to control. Restricting the feed intake of broiler breeder pullets during rearing was effective in controlling the number of normal yellow follicles only after 14 weeks of age [4]. Feed restriction effective in controlling of development of excess yellow follicles [10]. Restricting the quantity of food during rearing limits the production of yellow follicles and the incidence of double ovulations, leading to an increase in the number of eggs laid [3]. Alvarez and Hocking [11], found that reducing ovarian yellow follicle numbers by means of genetic selection could reduce the degree of feed restriction currently used in broiler breeder commercial stocks while maintaining total egg production. Reduction in yellow follicles, double ovulations, and double hierarchy leading to an increase in the number of eggs laid [3]. However, under the present study, a significant increase in egg production was not recorded in feed restricted group as compared to control. Interaction of phytoestrogen and feed restriction on high (HRD) and low (LRD) body weight birds reduced number of yellow follicles significantly $(\mathrm{p}<0.05)$ in comparison with control high (HFC) and low (LFC) body weight birds, respectively. The reduction in a number of yellow follicles may also help in correction of abnormal hierarchy (double hierarchy).

\section{Number of yellow atretic follicles (\%)}

The results on the number of yellow atretic follicles are given in Table-2. Number of yellow atretic follicles was observed 50\% in control (HFC) and it was reduced to $16 \%$ by phytoestrogens in HFD but no any difference was observed LFD as per their control. Hocking and Whitehead [12], suggested that more normal white follicles and lower proportions of atretic ones in lean line birds at 34 weeks than in the fat line. In the present study, a decreasing trend in fat level by phytoestrogen is also indicated. Hence, somehow, phytoestrogen in HFC group had been helpful in declining the incidence of atresia.

Feed restriction reduced number of yellow atretic follicles percentage in both high (HRC) and low (LRC) body weight birds. Thus, there exists a positive linear relationship between body weight and the proportion of yellow atretic follicles and internal ovulation. Due to intense selection pressure with growth as sole criteria increased the incidence of atretic follicles and internal ovulation and are the major causes of poor rates of lay in breeder females [13]. Interaction of phytoestrogen and feed restriction on high (HRD) body weight birds reduced number of yellow atretic follicles as compared to control (HFC) and no any difference in case of low body weight birds (LRD). The number of small atretic ovarian follicles were 0.68 more in ad libitum-fed pullets compared with restricted pullets [9].

\section{Oviduct weight}

The results on the oviduct weight are available in Table-2. Phytoestrogen improved numerically weight of the oviduct in both high (HFD) and low (LFD) body weight birds as compared to their respective controls. Cain et al. [14] administered the individual isoflavone (Coumestrol and Biochanin-A) to captive scales quail and found slight induction of oviduct growth. Similarly, phytoestrogens increase oviduct mass in ducks and hens $[14,15]$. Feed restriction in LRC birds significantly $(\mathrm{p}<0.05)$ reduced oviduct weight in comparison to control (LFC). Since oviduct maturation is regulated by ovary and under the present study feed restriction suppressed ovarian development which is supported by other workers [10] as well and thus it is but natural that feed restriction can slow down development of oviduct.

In high body weight birds interaction of phytoestrogen and feed restriction (HRD), oviduct weight not significantly but numerically increased as compared to control birds. In low body weight group, the oviduct weight reduced significantly in LRD group. This shows that feed restrictions impact on lowering of the oviduct weight is neutralized by phytoestrogen, but same could not be done in birds with low body weight.

\section{Presence of internal ovulation}

The results on presence of internal ovulation (Figure-1) are presented in Table-2. Treatment of birds with phytoestrogen minimized internal laying problem which was mainly occurred in birds of heavy body weight only but no difference in LFD in comparison to control birds. Internal ovulation at sexual maturity has been proposed to result from a lack of synchrony between the maturation of the oviduct and ovary [16].

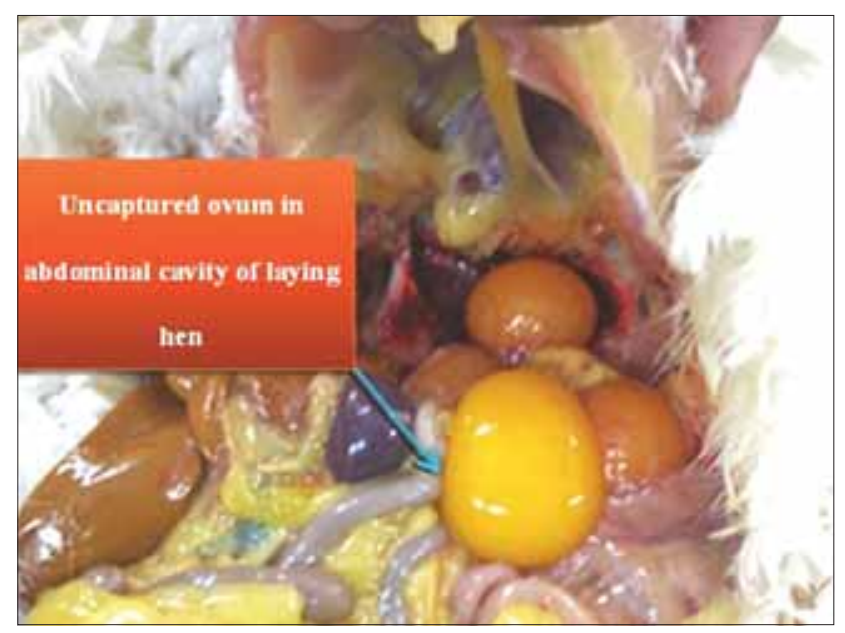

Figure-1: Uncaptured ovum in the abdominal cavity of broiler breeder hens (Internal ovulation). 
In broiler breeders and heavy turkeys, ovary develops faster than the oviduct so that there was a high incidence of internal ovulation. Genistein (phytoestrogen) has been shown to induce oviduct growth in hens [15], proposed to synchronize ovary and oviduct growth. It has been suggested that excessive BW gain, brought on by overfeeding of pullets during the reproductive development phase of production, accelerates ovarian follicular maturation such that more ovulations occur than the oviduct can effectively process [2]. The release of several follicles from the ovary at a similar time (multiple ovulations) during the ovulatory cycle sometimes makes it difficult for the infundibulum to capture all the follicles that are ovulated which resulted in internal ovulation [3]. Feed restriction and interaction of phytoestrogen and feed restriction have no any effective role in reduction of internal laying in high (HRC and HRD) and low (LRC and LRD) body weight birds as compared to control but they have reduced double hierarchy. Earlier studies have reported about 30\% incidences of internal laying in birds during early laying phase [17]. Such laying anomalies may have aggravated in modern breeds particularly in broilers due to heavy selection pressure for rapid growth [18].

\section{Presence of abnormal hierarchy}

The results on presence of abnormal hierarchy are presented in Table-2. Phytoestrogen supplementation suppressed the incidence of double hierarchy irrespective of body weight. Controversial positive and negative effects of phytoestrogen on reproduction have been reported; earlier studies suggest that the phytoestrogen may cause follicular abnormalities, infertility in birds (quail), and decline in egg laying [19]. However, in recent studies, Liu et al. [20] reported that daidzein stimulated germ cell proliferation in the chicken embryonic ovary, and daidzein increased laying performance, follicle development. Feed restriction reduced double hierarchy in high and low body weight birds in comparison to controls. Low egg production during early lay in broiler breeders fed ad libitum is associated with multiple ovulations caused by the presence of at least two hierarchies of ovarian yellow follicles. Restricting the quantity of food during rearing limits the production of yellow follicles and the incidence of double ovulations, leading to an increase in the number of eggs laid [3]. A positive relationship between body weight and the number of yellow follicles exists in broiler, duck, and turkey breeding females which were restricted after 14 weeks [4]. Phytoestrogen and feed restriction together did not prove superior over individual treatment.

\section{Conclusion}

It is concluded that phytoestrogens and limited feed restriction likely to improve reproductive efficiency around age of sexual maturity by overcoming the reproductive anomalies and modulating the ovarian and oviduct maturation favorably in broiler breeder hen.

\section{Authors' Contributions}

ADM and RPM designed the experiment. ASS, LC, and VS helped to ADM to carry out research, to collect and analyze data. Manuscript reviewed and revised by RPS, JM, ADM, ASS, LC, and VS. All authors read and approved the final manuscript.

\section{Acknowledgment}

The authors are thankful to the Director, CARI and IVRI, Izatnagar, for providing necessary funds and facilities at the time of research.

\section{Competing I nterests}

The authors declare that they have no competing interests.

\section{References}

1. McDerment, N.A., Wilson, P.W., David, W., Dunn, I.C. and Hocking, P.M. (2012) Identification of novel candidate genes for follicle selection in the broiler breeder ovary. BMC Genomics, 13: 494

2. Siegel, P.B. and Dunnington, E.A. (1985) Reproductive complications associated with selection for broiler growth. In: Hill, W.G., Manson, J.M. and Hewitt, D., editor. Poultry Genetics and Breeding. British Poultry Science Ltd., Harlow, UK. p59-72.

3. Hocking, P.M., Waddington, D., Walker, M.A. and Gilbert, A.B. (1987) Ovarian follicular structure of white Leghorns fed ad libitum and dwarf and normal broiler breeders fed ad libitum or restricted to point of lay. $\mathrm{Br}$. Poult. Sci., 28(3): 493-506.

4. Hocking, P.M., Waddington, D., Walker, M.A. and Gilbert, A.B. (1989) Control of the development of the ovarian follicular hierarchy in broiler breeder pullets by food restriction during rearing. Br. Poult. Sci., 30(1): 161-174.

5. Eitan, Y. and Soller, M. (2009) Problems associated with broiler breeder entry in to lay: A review and hypothesis. Worlds Poult. Sci. J., 65: 641-649.

6. Jaap, R.G. and Muir, F.V. (1968) Erratic oviposition and egg defects in broiler-type pullets. Poult. Sci., 47: 417-423.

7. Leksrisompong, N. (2010) Ph.D. Thesis. Effects of feeder space and feeding programs during rearing and laying on broiler breeder reproductive performance and livability. A Dissertation Submitted to the Graduate Faculty of North Carolina State University. Animal Science and Poultry Science.

8. Snedecor, G.W. and Cochran, W.G. (1989) Statistical Methods. $8^{\text {th }}$ ed. The Iowa State University Press, Iowa.

9. Duncan, D.B. (1955) Multiple range and F tests. Biometrics, 11: $1-42$

10. Sun, J.M., Richards, M.P., Rosebrough, R.W., Ashwell, C.M., McMurtry, J.P. and Coon, C.N. (2006) The relationship of body composition, feed intake, and metabolic hormones for broiler breeder females. Poult. Sci., 85(7): 1173-1184.

11. Alvarez, R. and Hocking, P.M. (2009) Stochastic modelling of optimum initial body weight, daily weight gain and effect of genetic changes in ovulation rate and age at sexual maturity on total egg production of broiler breeders. Br. Poult. Sci., 50(1): 135-143.

12. Hocking, P.M. and Whitehead, C.C. (1990) Relationship between body fatness, ovarian structure and reproduction in mature females from lines of genetically lean or fat broilers given different food allowances. Br. Poult. Sci., 31: 319-330. 
13. Decuypere, E., Boonen, R., Bruggeman, V., Li, Y., Koppenol, A., Tavernier, J., Janssens, S. and Everaert, N. (2012) The broiler breeder paradox from an ethical, genetic and physiological perspective and suggestions for solutions. Area: Chicken Breeder and Broiler Production. XXIV World's Poultry Congress 5-9 August, 2012. Brazil.

14. Cain, J.R., Lien, R.J., Beasom, S.L. (1987) Phytoestrogen effects on reproductive performance of scaled quail. J. Wildlife Manag., 51: 198-201.

15. Awadein N.B., Eid Y.Z. and El-Ghany F.A.A. (2010) Effect of dietary supplementation with phytoestrogens sources before sexual maturity on productive performance of mandarah hens. Egypt. Poult. Sci., 30(III): 829-846.

16. Melnychuk, V.L., Robinson, F.E., Renema, R.A., Hardin, R.T., Emmerson, D.A. and Bagley, L.G. (1997) Carcass traits and reproductive development at the onset of lay in two lines of female turkeys. Poult. Sci., 76(9): $1197-1204$

17. Wood-Gush, D.G.M. and Gilbert, A.B. (1965) Observation on the relationship between the ovary and the oviduct in the domestic hens. Nature, 207: 1210-1211.

18. Moudgal, R.P., Sirajudeen, M., Sastry, K.V.H., Tyagi, J.S. and Mohan, J. (2010) Cause of internal laying revealed. CARI News, 25(1): 1-2.

19. Saiafzadeh, S. and Jahanian, R. (2013). Effect of soy isoflavones on ovarian follicle dynamics and bone mineral content in leghorn laying hens. $19^{\text {th }}$ European Symposium on Poultry Nutrition. Potsdam, Germany, August 26-29, 2013.

20. Liu, H.Y., Zhang, C.Q. and Zeng, W.D. (2006) Estrogenic and antioxidant effects of a phytoestrogen daidzein on ovarian germ cells in embryonic chickens. Domest. Anim. Endocrinol., 31: 258-268. 